\title{
Anatomical Breast Imaging Derived Parameters Do Not Provide Incremental Information In Prediction of Nonvisualization of Sentinel Lymph Nodes On Lymphoscintigraphy
}

Youssef Chahid ( $\nabla$ y.chahid@amsterdamumc.nl )

Amsterdam UMC, location AMC

Hein J. Verberne

Amsterdam UMC, location AMC

Edwin Poel

Amsterdam UMC, location AMC

N. Harry Hendrikse

Amsterdam UMC, location VUmc

Jan Booij

Amsterdam UMC, location AMC

\section{Research Article}

Keywords: lymphoscintigraphy, nonvisualization, sentinel lymph node, breast cancer, mammography, breast MRI

Posted Date: January 3rd, 2022

DOI: https://doi.org/10.21203/rs.3.rs-1187890/v1

License: (c) (i) This work is licensed under a Creative Commons Attribution 4.0 International License.

Read Full License 


\section{Abstract}

Background: Accurate sentinel lymph node (SLN) staging is essential for both prognosis and treatment in patients with breast cancer. However, the preoperative lymphoscintigraphy may fail to visualize the SLN. The aim of this retrospective study was to investigate whether parameters derived from anatomical breast imaging can predict SLN nonvisualization on lymphoscintigraphy. For this single-center retrospective study all data of mammography, breast magnetic resonance imaging (MRI), and lymphoscintigraphy of SLN procedures from January 2016 to April 2021 were collected and reviewed from the Amsterdam UMC electronic health records database.

Results: A total of 758 breast cancer patients were included in this study. The SLN nonvisualization rate was $29.7 \%$ on lymphoscintigraphy. Multivariable analysis showed that age $\geq 70$ years $(P=0.019$; OR: 1.82; $95 \% \mathrm{Cl}: 1.10-3.01), \mathrm{BMI} \geq 30 \mathrm{~kg} / \mathrm{m}^{2}$ ( $\mathrm{P}=0.031$; OR: $1.59 ; 95 \% \mathrm{Cl}: 1.04-2.43$ ), and nonpalpable tumors ( $\mathrm{P}=0.034$; OR: $1.54 ; 95 \% \mathrm{Cl}: 1.03-2.04)$ were independent predictors of SLN nonvisualization. Differences in tumor size, Breast Imaging-Reporting and Data System (BI-RADS) classification, or breast density were not significantly associated with SLN nonvisualization.

Conclusions: This study shows that, by using a multivariable analysis, risk factors for SLN nonvisualization in breast cancer patients during preoperative lymphoscintigraphy are age $\geq 70$ years, $\mathrm{BMI} \geq 30 \mathrm{~kg} / \mathrm{m}^{2}$, and nonpalpable tumors. Parameters derived from mammography or breast MRI, however, are not useful to predict SLN nonvisualization on lymphoscintigraphy.

\section{Background}

Accurate sentinel lymph node (SLN) staging is essential for both prognosis and treatment in patients with breast cancer selected to undergo a SLN procedure (1). However, preoperative lymphoscintigraphy may fail to visualize the SLN. In the literature, reported rates of SLN nonvisualization vary between 2 and $28 \%$ $(2-7)$. After investigation of a large dataset of breast cancer patients $(n=1462)$ we recently reported that age $\geq 70$ years $(P<0.001 ;$ OR: 2.27; 95\% Cl: $1.46-3.53)$, body mass index $(\mathrm{BMI}) \geq 30 \mathrm{~kg} / \mathrm{m}^{2}(\mathrm{P}=0.031$; OR: 1.48; 95\% Cl: 1.04-2.12), and non-palpable tumors ( $\mathrm{P}=0.004$; OR: 1.54; $95 \% \mathrm{Cl}: 1.15-2.07)$ were independent predictors of SLN nonvisualization on lymphoscintigraphy (8). These findings were in accordance with findings of some previous studies (2-7).

Shortly after our publication, however, Quak and co-workers showed an interesting association between breast density and SLN nonvisualization (9). They found that breasts with fatty or scattered fibroglandular densities were strongly associated with higher age $(P<0.001)$, higher BMI $(P<0.001)$, and nonvisualization ( $P=0.042)$. However, due to a lack of a multivariable analysis, it was not possible to assess the influence of breast density in relation to other risk factors for SLN nonvisualization (10).

Therefore the purpose of this retrospective study was to reproduce the claim that breast density is an independent predictor of SLN nonvisualization on lymphoscintigraphy. 


\section{Methods}

\section{Patient population and data extraction}

Selected patients of this study were part of a single-center retrospective study investigating lymphoscintigraphy data of SLN procedures for risk factors for nonvisualization (8). This study was approved by the local Medical Ethics Review Committee. Data of SLN procedures were collected from January 2016 to April 2021 and reviewed. The following data were collected from the Amsterdam UMC, location AMC, electronic health records database: age (divided into three categories: $<50$ years, 50-70 years, and $\geq 70$ years) (6), BMI (divided into three categories: $<25 \mathrm{~kg} / \mathrm{m}^{2}, 25-30 \mathrm{~kg} / \mathrm{m}^{2}$, and $\geq 30$ $\mathrm{kg} / \mathrm{m}^{2}$ ) (5), tumor palpability (divided into two categories: palpable and nonpalpable tumor) (6), and tumor location (divided into two categories: lateral and medial/central) (6), and tumor size (divided into three categories: < $20 \mathrm{~mm}$ (T-stage 1), 20-50 mm (T-stage 2), and > $50 \mathrm{~mm}$ (T-stage 3)) (6). The following characteristics were divided based on the distribution of our data: Breast Imaging-Reporting and Data System (BI-RADS) classification (divided into classification $\leq 5$ and classification 6 ) and breast density categories (divided into $\leq 50 \%$ fibroglandular density (categories A or B) and $>50 \%$ fibroglandular density (categories $\mathrm{C}$ or $\mathrm{D})$ ) (11).

\section{Lymphoscintigraphy imaging protocol}

Technetium-99m-labeled albumin nanocolloid (from January 2016 to February 2019: Nanocoll, GE Healthcare, the Netherlands; from March 2019 to April 2021: Nanoscan, Radiopharmacy, Hungary) was administrated via an intra-tumoral injection, by a resident or an experienced nuclear medicine physician, either by palpation in palpable tumors or ultrasound-guided in nonpalpable tumors. Approximately 120 MBq technetium-99m-labeled albumin nanocolloid in a volume of $0.25 \mathrm{~mL}$ was administered. Planar lymphoscintigraphy was performed at 15 minutes and 2 hours post-injection intervals. Focal accumulations in at least one axillar lymph node was defined as SLN. SLN nonvisualization was clinically classified as nonvisualization when no SLN was visualized on routine clinical lymphoscintigraphy, as earlier described (8).

\section{Breast imaging protocol}

Breast imaging was visually assessed by an experienced radiologist in accordance with the 5th edition of BI-RADS lexicon on mammography and/or breast magnetic resonance imaging (MRI). All available data of BI-RADS classification (0-6), breast density (categories A-D), and tumor diameter were collected from the electronic health records.

\section{Statistical analysis}

Patient and tumor characteristics were evaluated using descriptive statistics. Univariate logisticregression models were used to examine the relationships between the different characteristics and SLN nonvisualization. Pearson Chi-Square exact test was used for categorical variables and the MantelHaenszel exact test was used for ordinal variables. Variables with a P value below $10 \%$ in the univariate 
analysis were included for the multivariable logistic-regression models. All statistical tests were two-tailed and a $P$ value below $5 \%$ was considered statistically significant. Odds ratios (ORs) of significant risk factors are presented with calculation of $95 \%$ confidence interval $(\mathrm{Cl})$. All analysis were performed with IBM SPSS Statistics (version 26, IBM, USA).

\section{Results}

\section{Preoperative lymphoscintigraphy}

A total of 758 breast cancer patients were enrolled in this study. Mean patient age was 59.8 years (SD 12.0 years) and the mean BMI was $27.7 \mathrm{~kg} / \mathrm{m}^{2}$ (SD $5.6 \mathrm{~kg} / \mathrm{m}^{2}$ ). Preoperatively, the $S L N$ was visualized on planar lymphoscintigraphy in $70.3 \%(533 / 758)$ of the SLN procedures and nonvisualization occurred in $29.7 \%(225 / 758)$ of the SLN procedures. A total of 299 patients had breast density categories A (30/299) or $B(269 / 299)$, and 170 patients had breast density category C $(128 / 170)$ or category $D(42 / 170)$.

\section{Risk factors of SLN nonvisualization}

Table 1 presents the number of SLN procedures with nonvisualization at planar lymphoscintigraphy. The multivariable analysis showed that age $\geq 70$ years ( $P=0.019 ; \mathrm{OR}: 1.82 ; 95 \% \mathrm{Cl}: 1.10-3.01), \mathrm{BMI} \geq 30$ $\mathrm{kg} / \mathrm{m}^{2}(\mathrm{P}=0.031$; OR: $1.59 ; 95 \% \mathrm{Cl}: 1.04-2.43)$, and nonpalpable tumors $(\mathrm{P}=0.034 ; \mathrm{OR}: 1.54 ; 95 \% \mathrm{Cl}$ : 1.03-2.04) were independent predictors of SLN nonvisualization on lymphoscintigraphy. Differences in tumor size and BI-RADS classification did not lead to a significant increased risk for SLN nonvisualization. 
Table 1

Results of multivariable analysis for risk factors of sentinel lymph node nonvisualization on lymphoscintigraphy after initial injection of the radiotracer

\begin{tabular}{|c|c|c|c|c|c|}
\hline \multirow[t]{2}{*}{ Characteristics } & \multirow[t]{2}{*}{$\mathbf{N}$} & \multirow[t]{2}{*}{$\begin{array}{l}\mathrm{N} \text { of } \\
\text { nonvisualization (\%) }\end{array}$} & \multirow{2}{*}{$\begin{array}{l}\begin{array}{l}\text { Univariate } \\
\text { analysis }\end{array} \\
\text { P-value }\end{array}$} & \multicolumn{2}{|c|}{ Multivariable analysis } \\
\hline & & & & $\begin{array}{l}\text { Adjusted OR (95\% } \\
\text { Cl) }\end{array}$ & $\begin{array}{l}P \text { - } \\
\text { value }\end{array}$ \\
\hline Age (years) & 166 & $40(24.1)$ & $0.001^{a}$ & 1 & 0.985 \\
\hline$<50$ & 417 & $114(27.3)$ & & $1.00(0.65-1.56)$ & 0.019 \\
\hline $50-70$ & 175 & $71(40.6)$ & & $1.82(1.10-3.01)$ & \\
\hline \multicolumn{6}{|l|}{$\geq 70$} \\
\hline $\mathrm{BMI}\left(\mathrm{kg} / \mathrm{m}^{2}\right)$ & 236 & $59(25.0)$ & $0.007^{a}$ & 1 & 0.138 \\
\hline$<25$ & 223 & $72(32.3)$ & & $1.37(0.90-2.07)$ & 0.031 \\
\hline $25-30$ & 197 & $73(37.1)$ & & $1.59(1.04-2.43)$ & \\
\hline$\geq 30$ & 102 & & & & \\
\hline \multicolumn{6}{|l|}{ Unknown } \\
\hline Tumor palpability & 447 & $109(24.4)$ & $<0.001^{b}$ & 1 & 0.034 \\
\hline Palpable & 311 & $116(37.3)$ & & $1.54(1.03-2.04)$ & \\
\hline \multicolumn{6}{|l|}{ Nonpalpable } \\
\hline Tumor size $(\mathrm{mm})$ & 541 & $159(29.4)$ & $0.969^{a}$ & & \\
\hline$<20$ & 143 & $42(29.4)$ & & & \\
\hline $20-50$ & 14 & $4(28.6)$ & & & \\
\hline$>50$ & 60 & & & & \\
\hline \multicolumn{6}{|l|}{ Unknown } \\
\hline \multirow{4}{*}{$\begin{array}{l}\text { BI-RADS } \\
\text { classification } \\
\leq 5\end{array}$} & 187 & $50(26.7)$ & $0.218^{b}$ & & \\
\hline & 442 & 140 (31.7) & & & \\
\hline & 129 & & & & \\
\hline & & & & & \\
\hline Unknown & & & & & \\
\hline
\end{tabular}

a Mantel-Haenszel exact test for ordinal variables

b Pearson Chi-Square exact test for categorical variables 


\begin{tabular}{|lllll|}
\hline Characteristics & $\mathbf{N}$ & $\begin{array}{l}\text { N of } \\
\text { nonvisualization (\%) }\end{array}$ & $\begin{array}{l}\text { Univariate } \\
\text { analysis }\end{array}$ & \multicolumn{2}{l|}{ Multivariable analysis } \\
\cline { 3 - 5 } & & P-value & $\begin{array}{l}\text { Adjusted OR (95\% } \\
\text { Cl) }\end{array}$ & $\begin{array}{l}\text { P- } \\
\text { value }\end{array}$ \\
\hline $\begin{array}{l}\text { Breast density } \\
\text { category }\end{array}$ & 299 & $95(31.8)$ & $0.030^{\mathrm{b}}$ & \\
A or B & 170 & $38(22.4)$ & & \\
C or D & 289 & & & \\
Unknown & & & \\
\hline a Mantel-Haenszel exact test for ordinal variables & & \\
\hline b Pearson Chi-Square exact test for categorical variables & \\
\hline
\end{tabular}

\section{Breast density}

The association of breast density categories, age and $\mathrm{BMI}$ is shown in table 2 . The breast density categories $A$ or $B$ were significant associated with a higher age $(P<0.001)$ and $B M I(P<0.001)$. The univariate analysis showed that breasts with $\leq 50 \%$ fibroglandular tissue was a predictor of SLN nonvisualization on lymphoscintigraphy (Table $1, \mathrm{P}=0.030$ ). When combined with age, $\mathrm{BMI}$, and tumor palpability in the multivariate analysis, however, breast density was not significantly associated with SLN nonvisualization on lymphoscintigraphy $(P=0.234)$. 
Table 2

Comparison of age and BMI of breast density categories

\begin{tabular}{|lllll|}
\hline Characteristics & N & $\begin{array}{l}\text { Breast density categories A or } \\
\mathbf{B}(\%)\end{array}$ & $\begin{array}{l}\text { Breast density categories C or } \\
\mathbf{D}(\%)\end{array}$ & $\begin{array}{l}\text { P- } \\
\text { value }\end{array}$ \\
\hline Age (years) & 135 & $62(45.9)$ & $73(54.1)$ & $<$ \\
$<50$ & 241 & $159(66.0)$ & $82(34.0)$ & \\
$50-70$ & 93 & $78(83.9)$ & $15(16.1)$ & \\
$\geq 70$ & 289 & & & \\
Unknown & & & $861^{\text {a }}$ \\
BMl (kg/m $\left.{ }^{2}\right)$ & 168 & $82(48.8)$ & $49(33.8)$ & \\
$<25$ & 145 & $96(66.2)$ & $10(9.4)$ & \\
$25-30$ & 106 & $96(90.6)$ & & \\
$\geq 30$ & 339 & & & \\
Unknown & & & \\
\hline a Mantel-Haenszel exact test for ordinal variables & & \\
\hline
\end{tabular}

\section{Discussion}

We found that age $\geq 70$ years, $\mathrm{BMI} \geq 30 \mathrm{~kg} / \mathrm{m}^{2}$, and non-palpable tumors were independent predictors of SLN nonvisualization on lymphoscintigraphy in breast cancer patients. These risk factors were recently discussed in detail in our previous publication (8).

To the best of our knowledge, this study is the first to examine the influence of BI-RADS classification on SLN nonvisualization. We also attempted to reproduce the claim that breast density is an independent predictor of SLN nonvisualization on lymphoscintigraphy (9). We here showed that BI-RADS classification, breast density, and tumor size were not significantly associated with SLN nonvisualization.

Breasts with fatty or scattered fibroglandular densities are less reported as a possible risk factor for SLN nonvisualization on lymphoscintigraphy (9). We found that breast cancer patients with less than $50 \%$ fibroglandular density are strongly correlated with higher ages and higher BMI values. These finding are in line with literature $(9,12)$. We attempted to reproduce the claim of Quak et al. that breast density is an independent predictor of SLN nonvisualization (9). We did find a significant effect of breast density categories on SLN nonvisualization in an univariate analysis, however, this effect was not significant in our multivariable model with predictors as age, BMI, and tumor palpability. The explanation for this phenomenon is that our multivariable model includes both age and BMI, which are strongly correlated with breast density. We conclude that information on breast density categories does not improve the already known multivariable model with age, BMI, and tumor palpability on SLN nonvisualization. 
Tumor size, or T-stage, is a well-studied and controversial parameter as risk factor for SLN nonvisualization on lymphoscintigraphy in breast cancer patients. Although two different studies reported in univariate analyses a significant correlation between tumor size $>20 \mathrm{~mm}$ and SLN nonvisualization lymphoscintigraphy in breast cancer patients, Hellingman et al. showed in a multivariable model an equal correlation between tumor size and $\operatorname{SLN}$ nonvisualization $(6,7,13)$. Despite this fact, we and the vast majority of other research groups were unable to find any significant effect of tumor size on SLN nonvisualization (2-5, 14-19).

To the best of our knowledge, this study is the first to examine the influence of BI-RADS classification on SLN nonvisualization. BI-RADS classification is a risk assessment tool, developed by American College of Radiology, that provides an approximate risk of malignancy to a lesion from zero to $\geq 95 \%$ (20). Despite the large amount of BI-RADS classification data, there was no significant association with SLN nonvisualization on lymphoscintigraphy in breast cancer patients.

One of the strengths of this study is the large number of breast cancer patients with lymphoscintigraphy data, which offered the opportunity to perform a multivariable analysis. However, this study has some limitations that need to be addressed. Because not all patients received breast imaging (i.e., mammography or breast MRI) before the SLN lymphoscintigraphy, we were unable to collect all data of BI-RADS classification, breast density, and tumor diameter from the electronic health records. Despite this limitation, the number of the patients in whom these parameters were registered had sufficient statistical power to examine the effect on SLN nonvisualization. Other limitations were that tumor grade and number of positive lymph nodes were not available. These factors could be confounders, since some studies have indications that these factors are possible associated with SLN nonvisualization $(2,3,13$, $15,16)$.

\section{Conclusions}

This study shows that, by using a multivariable analysis, risk factors for SLN nonvisualization in breast cancer patients during preoperative lymphoscintigraphy are age $\geq 70$ years, $\mathrm{BMI} \geq 30 \mathrm{~kg} / \mathrm{m}^{2}$, and nonpalpable tumors. Parameters derived from mammography or breast MRI, however, do not provide incremental information in the prediction of SLN nonvisualization on lymphoscintigraphy.

\section{Abbreviations}

SLN = sentinel lymph node

$\mathrm{BMI}=$ body mass index

BI-RADS = Breast Imaging-Reporting and Data System

$\mathrm{MRI}=$ magnetic resonance imaging 


\section{Declarations}

\section{Ethics approval and consent to participate}

Approval was obtained from the local ethics committee (reference number W20_255 \# 20.290).

\section{Consent for publication}

Not applicable.

\section{Availability of data and material}

The datasets used and/or analysed during the current study are available from the corresponding author on reasonable request.

\section{Competing interests}

The authors declare that they have no competing interests.

\section{Funding}

Not applicable.

\section{Authors' contributions}

$\mathrm{YC}$ and $\mathrm{EP}$ analyzed and interpreted the data. $\mathrm{YC}$ and $\mathrm{HV}$ were major contributors in writing the manuscript. $\mathrm{HH}$ and JB have substantively revised the manuscript. All authors read and approved the final manuscript.

\section{Acknowledgments}

Not applicable

\section{References}

1. Giammarile F, Alazraki N, Aarsvold JN, Audisio RA, Glass E, Grant SF, et al. The EANM and SNMMI practice guideline for lymphoscintigraphy and sentinel node localization in breast cancer. Eur $\mathrm{J} \mathrm{Nucl}$ Med Mol Imaging. 2013;40(12):1932-47.

2. Tanis PJ, van Sandick JW, Nieweg OE, Valdes Olmos RA, Rutgers EJ, Hoefnagel CA, et al. The hidden sentinel node in breast cancer. Eur J Nucl Med Mol Imaging. 2002;29(3):305-11.

3. Soran A, Falk J, Bonaventura M, Keenan D, Ahrendt G, Johnson R. Does failure to visualize a sentinel node on preoperative lymphoscintigraphy predict a greater likelihood of axillary lymph node positivity? J Am Coll Surg. 2007;205(1):66-71. 
4. Vaz SC, Silva A, Sousa R, Ferreira TC, Esteves S, Carvalho IP, et al. Breast cancer lymphoscintigraphy: Factors associated with sentinel lymph node non visualization. Rev Esp Med Nucl Imagen Mol. 2015;34(6):345-9.

5. Chakera AH, Friis E, Hesse U, Al-Suliman N, Zerahn B, Hesse B. Factors of importance for scintigraphic non-visualisation of sentinel nodes in breast cancer. Eur J Nucl Med Mol Imaging. 2005;32(3):286-93.

6. Hellingman D, Wan OY, de Wit-van der Veen BJ, van der Ploeg IM, Elkhuizen PHM, Rutgers EJT, et al. Predictive risk factors for sentinel lymph node nonvisualization on planar lymphoscintigraphy using an intratumoral injection in patients with primary breast cancer. Nucl Med Commun. 2019;40(4):317-24.

7. Goyal A, Newcombe RG, Mansel RE, Chetty U, Ell P, Fallowfield L, et al. Role of routine preoperative lymphoscintigraphy in sentinel node biopsy for breast cancer. Eur J Cancer. 2005;41(2):238-43.

8. Chahid Y, Qiu X, van de Garde EMW, Verberne HJ, Booij J. Risk factors for nonvisualization of the sentinel lymph node on lymphoscintigraphy in breast cancer patients. EJNMMI Res. 2021;11(1):54.

9. Quak E, Braux G, Weyts K, Lasnon C. More fat, less migration: breast density as a predictor of sentinel lymph node non-visualization in breast cancer. EJNMMI Res. 2021;11(1):112.

10. Chahid $Y$, Verberne HJ, Booij J. Response to letter: More fat, less migration: breast density as a predictor of sentinel lymph node non-visualization in breast cancer. EJNMMI Res. 2021;11(1):111.

11. Melnikow J, Fenton JJ, Whitlock EP, Miglioretti DL, Weyrich MS, Thompson JH, et al. Supplemental Screening for Breast Cancer in Women With Dense Breasts: A Systematic Review for the U.S. Preventive Services Task Force. Ann Intern Med. 2016;164(4):268-78.

12. Nykanen A, Okuma H, Sutela A, Masarwah A, Vanninen R, Sudah M. The mammographic breast density distribution of Finnish women with breast cancer and comparison of breast density reporting using the 4(th) and 5(th) editions of the Breast Imaging-Reporting and Data System. Eur J Radiol. 2021;137:109585.

13. Lo YF, Hsueh S, Ma SY, Chen SC, Chen MF. Clinical relevance of nonvisualized sentinel lymph nodes in unselected breast cancer patients during lymphoscintigraphy. Chang Gung Med J. 2005;28(6):378-86.

14. Birdwell RL, Smith KL, Betts BJ, Ikeda DM, Strauss HW, Jeffrey SS. Breast cancer: variables affecting sentinel lymph node visualization at preoperative lymphoscintigraphy. Radiology. 2001;220(1):4753.

15. Krausz Y, Ikeda DM, Jadvar H, Langleben D, Birdwell R, Strauss HW. Non-visualization of sentinel lymph node in patients with breast cancer. Nucl Med Commun. 2001;22(1):25-32.

16. Brenot-Rossi I, Houvenaeghel G, Jacquemier J, Bardou VJ, Martino M, Hassan-Sebbag N, et al. Nonvisualization of axillary sentinel node during lymphoscintigraphy: is there a pathologic significance in breast cancer? J Nucl Med. 2003;44(8):1232-7.

17. Jansen JE, Bekker J, de Haas MJ, van der Weel FA, Verberne GH, Budel LM, et al. The influence of wire localisation for non-palpable breast lesions on visualisation of the sentinel node. Eur $\mathrm{J} \mathrm{Nucl}$ 
Med Mol Imaging. 2006;33(11):1296-300.

18. Rousseau C, Classe JM, Campion L, Curtet C, Dravet F, Pioud R, et al. The impact of nonvisualization of sentinel nodes on lymphoscintigraphy in breast cancer. Ann Surg Oncol. 2005;12(7):533-8.

19. Pritsivelis C, Garcia Mendonca CA, Pinheiro Pessoa MC, Coelho-Oliveira A, Gutfilen B, Barbosa Da Fonseca LM. Failure predictors of the sentinel lymph node in patients with breast cancer using Tc99m sulfur colloid and periareolar injection. Q J Nucl Med Mol Imaging. 2007;51(2):189-93.

20. Mercado CL. BI-RADS update. Radiol Clin North Am. 2014;52(3):481-7. 